\title{
Agricultural Commodity Price Forecasting using PSO-RBF Neural Network for Farmers Exchange Rate Improvement in Indonesia
}

\author{
Sarifah Putri Raflesia ${ }^{1}$, Taufiqurrahman ${ }^{2}$, Silfi Iriyani $^{3}$, Dinda Lestarini ${ }^{*}$ \\ ${ }^{1,4}$ Computer Science Faculty, Universitas Sriwijaya, Indonesia \\ ${ }^{2}$ Pusat Pertahanan Siber, Badan Instalasi Strategis Pertahanan Kementerian Pertahanan, Indonesia \\ ${ }^{3}$ Universitas Syiah Kuala, Indonesia \\ *dinda@unsri.ac.id
}

\begin{tabular}{l}
\hline Article Info \\
\hline Article history: \\
Received Sep 28, 2020 \\
Revised Aug 27, 2021 \\
Accepted Sep 26, 2021
\end{tabular}

\section{Keywords:}

Agricultural commodity RBFNN

PSO

Forecasting

\begin{abstract}
Agricultural commodity price forecasting becomes important for farmers since the knowledge of agriculture commodity price fluctuation can help the farmers to identify the right selling time. Recently, the absence of such the forecasting system makes the farmers decide to sell their commodities to middlemen which in turn, reduces their exchange rate as the length of distribution flow is complicated. The length of distribution flow is started from farmers, middlemen, wholesalers, retailers, and consumers. To address this problem, a forecasting system based on radial basis function neural network (RBFNN) is proposed. To optimize the network's learning process, particle swarm optimization (PSO)-based learning technique is applied. The RBFNN is chosen because of its ability to generally track irregular signal changing, good speed in learning process, and robustness. Meanwhile, the implementation of PSO aims to improve weight values towards global optimum in RBFNN model.
\end{abstract}

Copyright $(2021$ Institute of Advanced Engineering and Science. All rights reserved.

\section{Corresponding Author:}

Dinda Lestarini,

Computer Science Faculty,

Universitas Sriwijaya,

J1. Raya Palembang Prabumulih Km. 32, Indralaya, Sumatera Selatan, 30862, Indonesia.

Email: dinda.lestarini@gmail.com

\section{INTRODUCTION}

Agriculture can be defined as activities related to cultivation and management of plants and livestock to make ends meet humans [1]. Nowadays, agricultural sector faces main challenges: how to increase the amount of agricultural produce for support growth [2] and how to improve welfare of farmers in situations and conditions the reduced availability of natural resources.

Some of the problems are the reduced quality and quantity of water, decreasing soil fertility, climate change [3], and diminishing agricultural land fertile [4] which leads to urbanization of the population which ends in conflict in society. The problems faced by farmers are related to the process of managing agricultural products. Based on the farmer's perspective, the agricultural cycle is usually divided into three the main stages are [5], [6]:

- Pre-cultivation, starting with seed selection, land selection, scheduling, access to credit from government funding sources, and others.

- Crop cultivation and harvesting (planting and harvest), consisting of land preparation, seed sowing, management, water management and fertility, pest management, etc.

- Post-harvest (post-harvest), including marketing, transportation, packaging, and processing of agricultural products. 
Indonesia is an agricultural country with abundant natural wealth[7]. In Indonesia, agriculture is a sector that plays significant role in economic growth and also being an important source of income for people. The role of the agricultural sector in Indonesia's economy is very important because the sector is able to provide field employment for the majority of the Indonesian population live in the village and can also provide materials food for the population of Indonesia. It becomes the livelihood of the Indonesian people for centuries. Consequently, this sector gives an influential impact on culture and society of Indonesian people .

Moreover, the agricultural sector plays a role in the supply of materials raw for the industry and can provide foreign exchange income for non-oil and gas exports. The agricultural sector can be the guarantor of the economy of a country including Indonesia in the face of potential economic crises. According to Indonesia Law Number 19 year 2013 about farmers' protection and empowerment [8], government must facilitate every effort towards improvement of farmers' ability to carry out farming through education and training, counseling and mentoring, system development and agricultural marketing strategy, access to agriculture information, knowledge, and technology.

According to this fact, it is reasonable for the government to support the actors involved in this sector, especially farmers. The support lies from the formulation of strategic role in agricultural sectors, such as providing food for Indonesian population, generating foreign exchange through exports, providing industrial raw materials, increasing employment and business opportunities, increasing regional income, reducing poverty, and supporting other economic sectors.

The welfare of farmers can be measured by the farmer's exchange rate[9],[10]. Increased farmers' exchange rates indicate an increase in farmers' welfare and vice versa. Farmers 'exchange rates relate to farmers' ability to meet their household needs. If the farmer's income is greater than the increase in the price of agricultural production, which in turn affects its purchasing power, the farmers' ability to improve or increase their income. Briefly, there are three values of the farmer's value exchange [11]; (1) Farmers' exchange rate is more than 100 which means production price rises greater than its consumption, meaning that farmers 'income increases more than their expenditure so that farmers' income is greater than expenditure; (2) Farmers' exchange is equal to 100 means the farmers' experiences breakpoint.; (3) Farmers' exchange rate is under 100 means farmers are living in poverty. The increase in the price of production goods is relatively smaller compared to the increase in prices of consumer goods. The level of welfare of farmers in a period has decreased compared to the level of welfare of the previous period farmers.

According to Indonesian Central Bureau Statistics, Indonesian farmers' exchange rate continuously decreases[12]. Therefore, government needs to facilitate better information and knowledge to support farming activities which include cultivation, trading, or selling products in order to minimize risk and help farmers improve their quality of life.

One of the supports that have been given by the Indonesian government is the implementation of information technology (IT) to gather and provide agricultural data for decision-making purpose. It is reasonable since IT innovations are constantly emerging and leading to the development of new products and innovative applications, which in turn, can bring benefits and values to Indonesian and government. Recently, IT is useful to be an indicator of modernization, security, and economic strength in a country. In the context of agricultural field, the Indonesian government's Vegetables Research Institute / Balai Penelitian Tanaman dan Sayuran (BALITSA) has developed mobile-based learning application to spread agricultural information and knowledge to Indonesian farmers. This application provides information about the agriculture products' sell and buy, seeds, fertilizers, and also enables communication between farmers and their agriculture instructors.

Unfortunately, even though the problems of information sharing have been solved, the existing system is unable to provide agricultural products' price prediction which can help farmers to decide the profitable selling or buying price of agricultural products. An idea of price prediction system can be considered to be an important solution to address such the issue. Such the system becomes crucial since it enables cost estimation for distribution and revenue. In addition, it also aims to reduce the number of farmers who sell their products to middlemen which also affects farmers' welfare. On the other hand, strategic level as decision-makers is more likely to produce better decisions to achieve profits and deflect risks [13]. According to this research background, a model of agricultural products market prediction is proposed.

Agricultural products price data are usually shaped in time series. Their forecasting has been carried out actively and become a concern using various methods such as statistical methods and artificial intelligence (AI) which refers to any machine that is able to replicate human cognitive skills in problem-solving. Various works related to agricultural price forecasting were reported [14], [15], [16], [17]. In Yu et al. [16], a backpropagated (BP) neural network with genetic algorithm (GA) as optimization technique was applied. Here, the BPNN was divided into three parts, i.e., BPNN structure determination, GA optimization, and BPNN prediction. However, BPNNs have difficulty in large computational complexity.

Previously, there has been reported the use of artificial neural network for univariate time-series agricultural prices [15]. In this work, the time-series data were modeled as auto-regressive integrated moving 
average (ARIMA). In this work, the inputs were time-series price data. The data was separated into linear and nonlinear data. For forecasting purposes, the neural network, i.e., time-delay neural network (TDNN) was used to identify the pattern of errors. It was claimed that the hybrid ARIMA-TDNN system can predict the price accurately.

The issue of uncertainties is caused by random factors in agricultural commodity market [17]. Here, a mind evolutionary algorithm (MEA) was combined with support vector machine (SVM). Additionally, the pattern of price was modeled by using fuzzy logic techniques. The fuzzy information granulation was used for time series data pre-processing. The fluctuation of time-series data were granulated into three levels, i.e., low, average, and high. As the result, the range of fluctuation can be identified. Therefore, the variance of the forecasted price can be predicted.

BP neural network has a problem with overfitting and computational complexity [16]. In this research, the model will be generated using a non-linear artificial intelligence technique namely radial basis function neural network (RBFNN). The association of agricultural prices with non-linear factors such as political and social factors causes agricultural prices prediction cannot be done using a linear approach because it can generate inaccurate calculations.

In generating prediction model, Radial BFNN has better performance[18],[19] since RBFNN is nonlinear and the output of the network is linear when it concerns adjustable weights by means the learning will speed up. The RBFNN has good speed in learning the data, effectively improves the accuracy, easy to get adapted, and robust. This algorithm defines gaussian function as its parallel function. Unfortunately, since the values in the input space is non-zero, the RBFNN has local approximation.

In this research, the prediction model is proposed to generate price forecasting. The proposed method used is that of RBFNN. In addition, Particle Swarm Optimization (PSO) is also proposed to improve weight values towards global optimum.

\section{RESEARCH METHODS}

The experiments used chili prices dataset from 1st January 2017 to 31st May 2019. The dataset was obtained from https://hargapangan.id/. The dataset is divided into 2 groups, namely training data and testing data with ratio of $80 \%$ and $20 \%$, respectively. In this research, the prediction model is proposed to generate agriculture price forecasting. The proposed method used is that of radial basis function-based neural network with particle swarm optimization (PSO)-based adaptation.

\subsection{Radial Basis Function-based Artificial Neural Network (RBFNN)}

Radial Basis Function-based Artificial Neural Network (RBFNN) is a class of neural network using radial basis function (RBF) in all of its hidden neurons. Typically, the RBFNN is widely used for various purposes, such as system identification, pattern recognition, adaptive control systems, and so forth [20], [21] Some advantages of RBFNNs are that such the network can compensate input noise properly, have a good ability to learn and make generalization of given data [20]. Comparing to another network like multilayer perceptron (MLP), the RBFNNs perform better in nonlinear signals by approximating errors in some locals. Meanwhile, MLP performs global approximation which may be less accurate to identify errors. As shown in Figure 1, an RBFNN consists of three layers, i.e., input, hidden, and output layer.

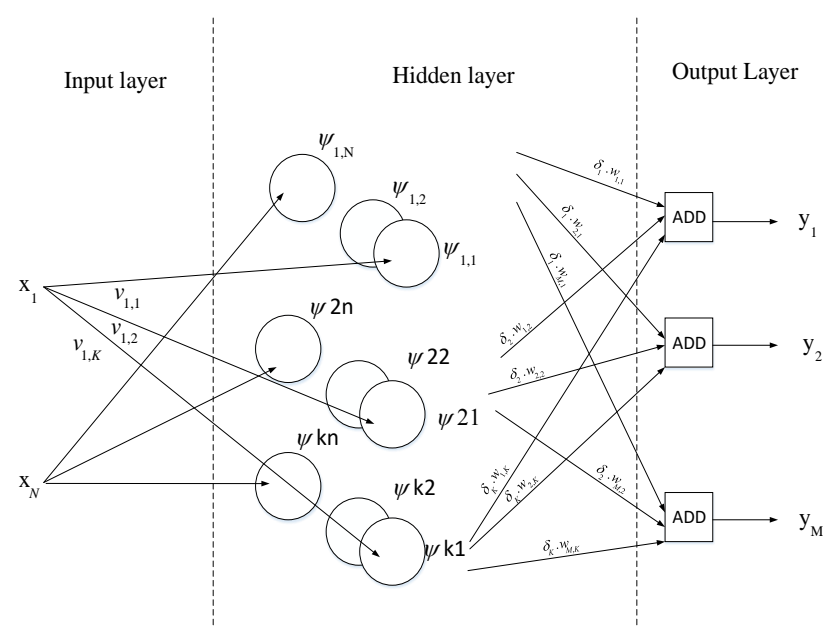

Figure 1. The working process of Artificial Neural Network (ANN) 
Each $k$-th layer in the hidden layer is constructed by $M$ neurons. For an RBFNN with $M$ inputs and $K$ outputs, let us define $\mathbf{Y}=\left[\begin{array}{llll}y_{1} & y_{2} & \ldots & y_{M}\end{array}\right]^{\mathrm{T}}$ as the output vector of the ANN; $\mathbf{X}$ as a vector of $N$-th inputs, i.e., $\mathbf{X}=\left[\begin{array}{llll}x_{1} & x_{2} & \ldots & x_{N}\end{array}\right]^{\mathrm{T}} ; \mathbf{W}$ as matrix of hidden neuron weights in correspondence to the outputs $\boldsymbol{Y}$ formulated as

$$
\mathbf{W}=\left[\begin{array}{cccc}
w_{1,1} & w_{1,2} & \ldots & w_{1, K} \\
w_{2,1} & w_{2,2} & \ldots & w_{2, K} \\
\cdots & \ldots & \ldots & \ldots \\
w_{M, 1} & w_{M, 2} & \ldots & w_{M, K}
\end{array}\right]
$$

where $w_{i, j}$ is the weight of the $\mathrm{j}$-th hidden neuron and the i-th output; $\boldsymbol{\Phi}=\left[\begin{array}{llll}\phi_{1} & \phi_{2} & \ldots & \phi_{K}\end{array}\right]$, where $\phi_{k}($.$) is defined as the product of sub-neurons \psi_{k, i}\left(x_{i}, \sigma_{k, i}, c_{k, i}\right)$, or formally,

$$
\phi_{k}\left(x(i), \mu_{k}, c_{k}\right)=\prod_{i=1}^{n} \psi_{k, i}\left(x_{i}, \sigma_{k, i}, c_{k, i},\right)
$$

Some well-known functions to apply as activation function are Gaussian functions, sigmoid functions, inverse multiquadric function, and so forth. In this paper, we apply Gaussian function as follows.

$$
\psi_{k, i}\left(x_{i}, \sigma_{k, i}, c_{k, i},\right)=\exp \left(-\left(x_{i}-c_{k, i}\right)^{2} / 2 \sigma_{k, i}^{2}\right)
$$

Where $c_{k, i}$ is the center of the $\mathrm{i}$-th hidden neuron related to the $\mathrm{i}$-th input, $\sigma_{\mathrm{k}, \mathrm{i}}$ is the standard deviation of the $j$-th hidden neuron in association to the $i$-th input. Finally, the output of the RBFNN is formulated as

$$
\mathbf{Y}=\mathbf{W} \boldsymbol{\Phi}
$$

Note that the proposed RBFNN, we set $w_{i, j}=0$ for all $i \neq j$ and $w_{i, j} \in \mathfrak{R}$ otherwise.

\subsection{Particle Swarm Optimization (PSO)}

Particle Swarm Optimization (PSO) is a meta-heuristic algorithm for optimization inspired by the interaction among a set of particles. This algorithm was coined in Clerc and Kennedy in 2002 [21] and has been applied in various research fields, such as robotics [21], operational research [22], control system [23] and so forth. The algorithm mimics the behavior of atomic-size particles which interacts among themselves in the presence of some "forces" among them. The phenomenon is used to solve optimization problems. The PSO system consists of a number of particles representing system's parameters which move closer to a particle whose objective function gives the smallest or largest value among others. An individual particle $\mathbf{p}$ in the swarm can be regarded as a set of decision variables. All of the particles have to move to a point with minimum/maximum fitness value. Let us define a particle of PSO as

$$
\mathbf{p}=\left\lfloor\begin{array}{llll}
w_{1,1} & w_{1,2} & \ldots & w_{M, K}
\end{array}\right\rfloor
$$

Where $M$ and $K$ are the number of output nodes and the number of hidden nodes, respectively. The objective is to find the minimum/maximum fitness value of an objective function $\mathrm{f}$. Note that in this paper we use two objective functions $f$. The first function is the root-mean square error (RMSE) defined as

$$
f=\sqrt{\frac{\sum_{i=1}^{M}\left(y_{i}-\hat{y}_{i}\right)^{2}}{M}}
$$

where $\hat{y}_{i}$ is defined as the forecast of the $i$-th output. In addition, we use the mean-absolute percentage error (MAPE) defined as

$$
f=\frac{100 \%}{M} \sum_{i=1}^{M}\left(\frac{y_{i}-\hat{y}_{i}}{\hat{y}_{i}}\right)
$$

In order to find the minimum fitness value, a series of iteration is used to determine the new positions of the vehicle. As particles in physics, each particle will move to a new position by adding the current position (or, the n-th position) to a velocity $\mathbf{v}$ defined as

$$
\mathbf{v}_{n+1}=\omega \mathbf{v}_{n}+c_{1} r_{1}\left(\mathbf{p}^{\text {lbest }}-\mathbf{p}_{n}\right)+c_{2} r_{2}\left(\mathbf{p}^{\text {gbest }}-\mathbf{p}_{n}\right)
$$


where $\omega$ is the inertial weight; $c_{1}$ and $c_{2}$ are constant learning rates; $r_{1}$ and $r_{2}$ are random numbers that are generated for each iteration; $\mathbf{p}^{\text {lbest }}$ is the local best particle, defined as the coordinate $\mathbf{W}$ of each particle with the lowest RMSE and MAPE that have been ever achieved measured from the first iteration until the current one; $\mathbf{p}^{\text {gbest }}$ is the global best particle, which is defined as the coordinate $\mathbf{W}$ related to the lowest RMSE and MAPE that have been ever achieved by all particles. The new position of $\mathbf{P}$, i.e., $\mathbf{P}_{n+1}$ is formulated as

$$
\mathbf{p}_{n+1}=\mathbf{p}_{n}+\mathbf{v}_{n+1} \text {. }
$$

\subsection{PSO-RBFNN based Prediction Model}

The agricultural comodity prices dataset is divided into training data and testing data with ratio of $80 \%$ and $20 \%$, respectively. The training data is used to build an appropriate PSO-RBFNN agricultural prediction model and the testing data is used to evaluate the model's performance. The required model to obtain is that with the weights in W that yields minimum RMSE and MAPE. In order to find the optimal weight matrix $\mathbf{W}$ we propose to use an RBFNN with weight tuning using the PSO algorithm. The prediction model used such method is called "PSO-RBFNN based prediction model".

Figure 2 shows the flowchart of agricultural commodity prices prediction model development. In this phase, RBFNN is implemented to build the agricultural commodity prices prediction model.

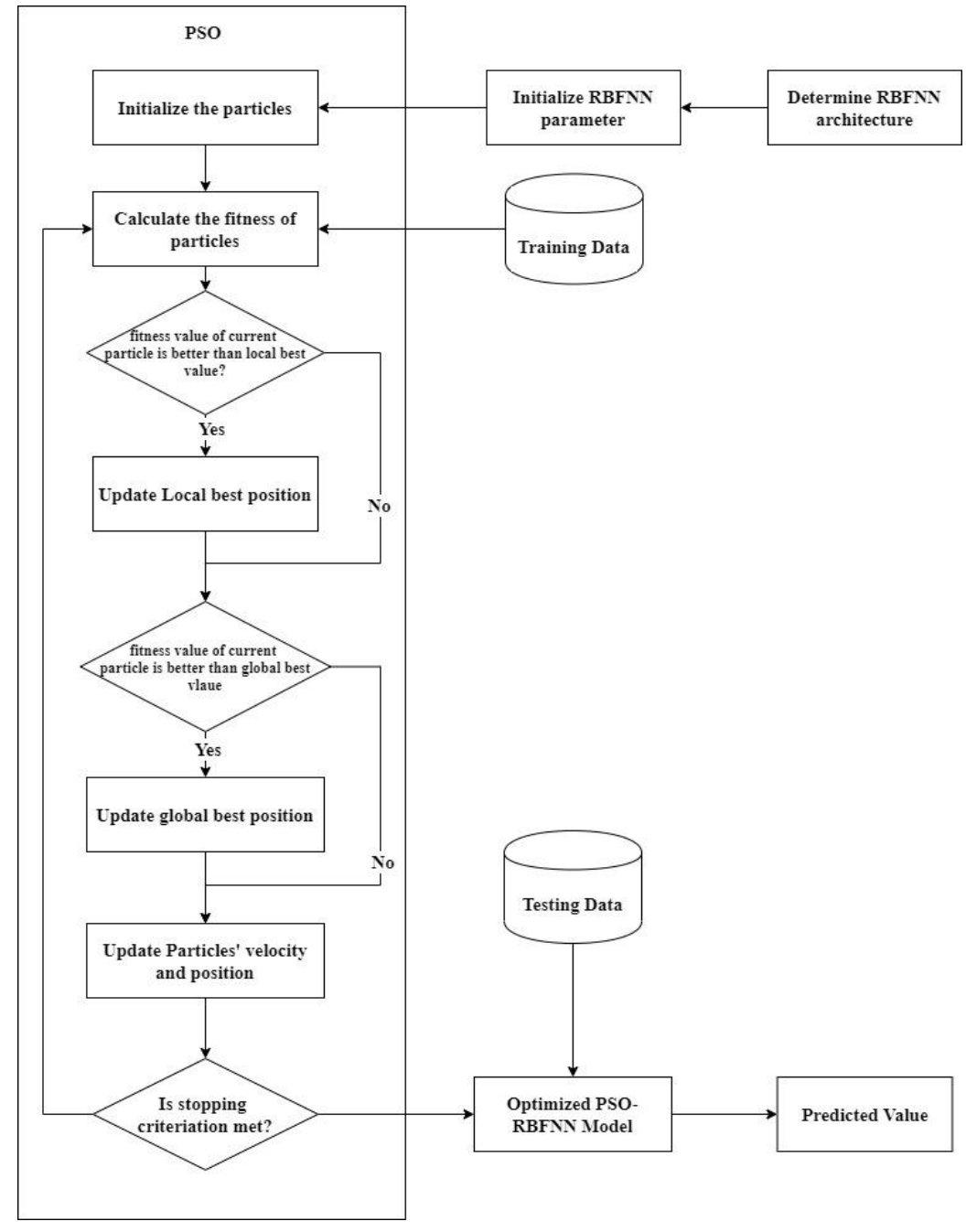

Figure 2. PSO-RBFNN flow chart

Meanwhile, PSO is also employed to gain a better prediction model by optimizing the connection weight between hidden and output layer. The development steps of the model are described as follows.

- Determine the RBFNN architecture.

In order to build agricultural commodity prices prediction model, we need to establish RBFNN architecture by determining the number of neurons in input layer, hidden layer and output layer. The number of neurons 
in input layer is obtained by using ACF and PACF analysis. Meanwhile, the number of neurons in hidden layer is obtained by trial and error.

- Initialize RBFNN parameters

In this step, RBFNN parameter (center point $c$, standard deviation $\sigma$, and weight $w$ ) was initialized. KMeans method was implemented to find the center points $c$ of the hidden layers which are also used to calculate the value of standard deviation $\sigma$. The connection weights between the hidden layer and the output layer were initialized with random numbers. Moreover, we employed Gaussian as activation function in hidden layer formulated in (3).

- Initialize the particles

In order to search the optimized value of weights, we also need to initialize PSO parameters, such as the number of particles $N$, the maximum number of iteration $k$, learning rate $\left(c_{1}\right.$ and $\left.c_{2}\right)$ and inertia weight $(\omega)$. Afterward, each particle $P$ is initialized with random position and velocity $v$ in $D$ dimensional search space. The minimum and maximum values of particle position are also specified to limit the search space.

- Calculate the fitness value for each particle

In every iteration, each particle will keep track of its whereabouts in search space to determine the best position achieved by particle $\mathbf{p}^{\text {lbest }}$ and the best position achieved by the swarm $\mathbf{p}^{\text {gbest }}$. In order to find the best solution of the problem, fitness value of $i$-th particle, $\mathbf{p}^{\text {lbest }}$ and $\mathbf{p}^{\text {gbest }}$ are calculated using predefined fitness function. We use two fitness functions, i.e., RMSE and MAPE which are defined in (6) and (7), respectively.

- Evaluate the fitness value of each particle

The fitness value of each particle is compared with the local best position $\mathbf{p}^{\text {lbest }}$. If the fitness value of $i$-th particle is better than the local best position $\mathbf{p}^{\text {lbest }}$, then the value of $\mathbf{p}^{\text {lbest }}$ is updated with the position of the $i$-th particle. The fitness value of $i$-th particle is also compared with population global best position $\mathbf{p}^{\text {gbest }}$. Similar to the previous process, when the fitness value of $i$-th particle is better than the global best position $\mathbf{p}^{\text {gbest }}$, then the value of $\mathbf{p}^{\text {gbest }}$ is updated with the position of the $i$-th particle.

- Update the particle velocity and position

In each iteration, the particle will update its position and velocity based on local best position $\mathbf{p}^{\text {lbest }}$ and global best position $\mathbf{p}^{\text {gbest }}$.

- Evaluate the stopping criterion

When the minimum fitness value is met or the maximum number of iteration is reached, then the search process is terminated. Otherwise, steps 4 to 7 will be repeated until the stopping criterion is met. When the search process terminated, the optimized agricultural commodity prices prediction model is obtained.

\section{RESULTS AND DISCUSSION}

In this section, we conduct experiments to evaluate the performance of agricultural commodity prices prediction model. Before training process, we need to determine the RBFNN architecture and parameter. In this study, we implemented an RBFNN architecture which consists of 3 neurons in input layer, 8 neurons in hidden layer and a neuron in output layer. According to this architecture, the training data is used to determine the center point of neurons in hidden layer $\mathrm{c}$ and spread $\sigma$, while the value of connection weights are initialized randomly. The PSO parameters are also set to find the optimized model. To evaluate the best solution in PSO, Mean Square error (MSE) is employed as fitness function. When the minimum fitness value is met or the maximum number of iteration is reached, then the search process is terminated. Otherwise, steps 4 to 7 will be repeated until the stopping criterion is met. When the search process terminated, the optimized agricultural commodity prices prediction model is obtained. Table 1 shows the parameters of PSO.

Table 1. PSO Parameter

\begin{tabular}{cc}
\multicolumn{2}{c}{ Table 1. PSO Parameter } \\
\hline Parameter & Value \\
\hline $\mathrm{N}$ & 20 \\
$\mathrm{k}$ & 100 \\
$\mathrm{c} 1$ & 1.5 \\
$\mathrm{c} 2$ & 2 \\
$\omega$ & 0.5 \\
\hline
\end{tabular}

After training, the RBFNN parameters are finalized. The agricultural commodity prices prediction model is tested using RMSE and MAPE. RMSE and MAPE are employed because they are one of the most applied methods to measure forecasting model performance. Table 2 shows the evaluation result of chili prices prediction model on testing and training data. Prediction result on training data show that value of MAPE range from 2.55 to 6.08 , while its range from 5.55 to 7.80 on testing data. As can be seen from the result, the agricultural commodity prices prediction model has a high accuracy. As a comparison, Figure 3 shows the actual and predicted agricultural commodity price on training and testing data. 
Table 2. Experiment Results

\begin{tabular}{ccccc}
\hline \multirow{2}{*}{ No } & \multicolumn{3}{c}{ Training Data } & \multicolumn{2}{c}{ Testing Data } \\
\cline { 2 - 5 } & RMSE & MAPE & RMSE & MAPE \\
\hline 1 & $2,750.36$ & 3.52 & $3,483.22$ & 5.80 \\
2 & $3,807.10$ & 4.68 & $3,284.75$ & 5.55 \\
3 & $4,281.30$ & 5.25 & $5,100.16$ & 6.03 \\
4 & $2,068.32$ & 2.89 & $4,702.95$ & 6.68 \\
5 & $5,414.88$ & 5.91 & $4,115.14$ & 7.50 \\
6 & $5,751.94$ & 6.08 & $3,566.12$ & 6.80 \\
7 & $3,826.81$ & 4.46 & $3,300.16$ & 6.74 \\
8 & $3,243.64$ & 4.04 & $4,650.12$ & 6.26 \\
9 & $1,919.86$ & 2.55 & $3,891.62$ & 6.02 \\
10 & $2,439.71$ & 3.25 &
\end{tabular}

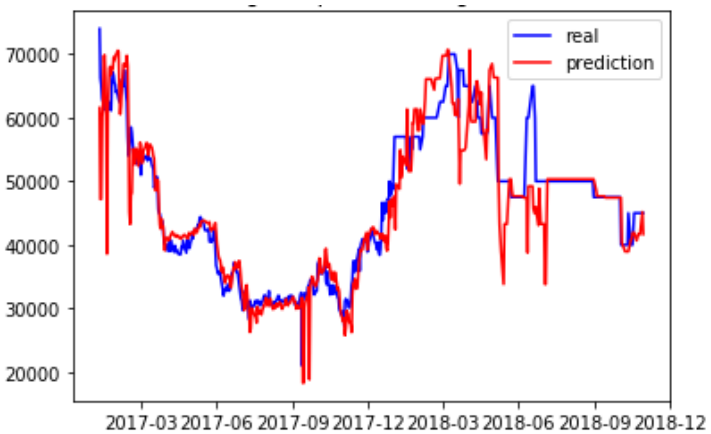

(a)

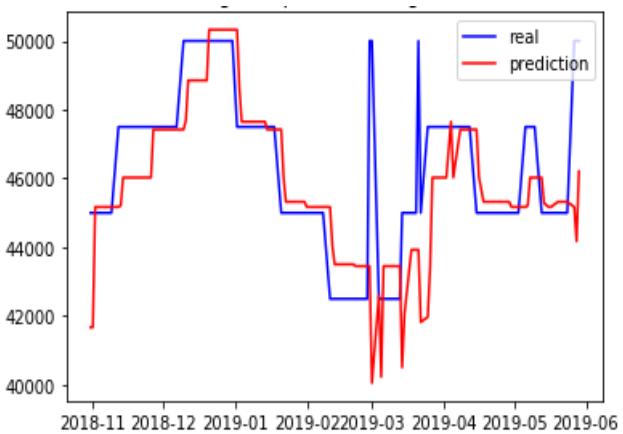

(b)

Figure 3. Results of model testing using training data and testing data.

Chili price forecasting using ANN [24] resulted in 16.19 MAPE value. This result is much higher than the forecasting model using PSO-RBFNN. Another research shows that the chili price forecasting using SVM, ANFIS, and SVM optimized with ANFIS resulted in $86.24 \%, 65.97 \%$ and $92.11 \%$ of accuracy respectively[25]. These results indicate that price forecasting model using PSO-RBFNN has a better performance in predicting chili price.

In the prediction by using training data, the real price can be predicted with relatively small error under 1000 iterations of training. However, some inaccurate prediction occurs in some spots. It indicates that additional training iterations are needed. Meanwhile, the prediction by using testing data shows visible discrepancy. It can be inferred from the experiment that the prediction performs large errors. However, the fluctuation pattern is similar. The real and predicted prices are differentiated by finite offsets. Based on these experiments, it can be concluded that the implementation of RBFNN and PSO can predict the pattern of fluctuation of the general commodity price.

\section{CONCLUSION}

In this research, the combination of RBFNN and PSO is applied to generate agricultural commodity prices forecasting model. The chili price dataset is used to generate and evaluate the forecasting model. Based on the experimental results, the combination of RBFNN and PSO produced high accuracy rate in predicting agricultural commodity price. The highest result obtained from experiments is $94,454 \%$. Furthermore, the determining factors of the agricultural commodity prices will be explored to improve the accuracy of forecasting system.

\section{ACKNOWLEDGMENTS}

The authors acknowledge Universitas Sriwijaya as funding institution. Also, to Database and Big Data Laboratory, Universitas Sriwijaya for facilitating the devices.

\section{REFERENCES}

[1] A. Zezza and L. Tasciotti, "Urban agriculture, poverty, and food security: Empirical evidence from a sample of developing countries," Food Policy, vol. 35, no. 4, pp. 265-273, 2010.

[2] J. W. Mellor, Agricultural development and economic transformation: promoting growth with poverty reduction. Springer, 2017.

[3] V. W. Ruttan, Sustainable agriculture and the environment: Perspectives on growth and constraints. CRC Press, 2019. 
[4] M. Khalifa and A. Gad, "Assessment of heavy metals contamination in agricultural soil of Southwestern Nile Delta, Egypt,” Soil Sediment Contam. An Int. J., vol. 27, no. 7, pp. 619-642, 2018.

[5] Y. Singh, "Information and communication technology (ICT) in agricultural and rural development--initiatives by government of India," Int. J. Eng. Sci. Humanit., vol. 2, no. 2, pp. 2250-3552, 2012.

[6] M. O. Najafabadi, S. M. Mirdamadi, and A. T. P. Najafabadi, "Designing a Mobile Training System in Rural Areas with Bayesian Factor Models,” Int. J. E-Learning, vol. 13, no. 1, pp. 23-39, 2014.

[7] K. M. Chomitz and C. Griffiths, "Deforestation, shifting cultivation, and tree crops in Indonesia: nationwide patterns of smallholder agriculture at the forest frontier," Poverty, Environ. Growth. World Bank, Washingt. DC.[Accessed on-line 2004.], 1996.

[8] B. Y. D. Nurfaidah and E. Rusdiyana, "Perception of field agricultural extension on the implementation of the law on protection and empowerment of farmers (republic of Indonesia law number 19 of 2013) in grobogan regency," $E \& E S$, vol. 456, no. 1, p. 12083, 2020.

[9] N. K. Bantilan, M. A. Wahyuningsih, and R. A. Rauf, "Improved Exchange Rate Farmers through Rice Falied Crop Intensification in Tolitoli , Indonesia," vol. 7, no. 1, pp. 1-6, 2018.

[10] T. Akbar, M. Fauzi, and H. Fajeri, "Affecting Factors Farmer Exchange Rate ( NTP ) of Food Crops South Kalimantan Province," vol. 12, no. 7, pp. 83-91, 2019.

[11] E. Ruauw, "Nilai tukar petani sebagai indikator kesejahteraan petani," J. Penelit. ASE, vol. 6, no. 2, pp. 1-8, 2010.

[12] M. I. Riyadh, "Analisis Nilai Tukar Petani Komoditas Tanaman Pangan di Sumatera Utara," J. Ekon. Kebijak. Publik, vol. 6, no. 1, pp. 17-32, 2015.

[13] S. P. Raflesia, A. K. Pamosoaji, S. Nurmaini, and D. Lestarini, "Conceptual Modeling for Intelligent KnowledgeBased System in Agriculture: Case Study of Indonesia," 2018 Int. Conf. Electr. Eng. Comput. Sci., vol. 17, pp. 397-402, 2018.

[14] G. Li, S. Xu, and Z. Li, "Short-term price forecasting for agro-products using artificial neural networks," Agric. Agric. Sci. Procedia, vol. 1, pp. 278-287, 2010.

[15] G. Jha, S. Das, S. Sinha, A. Lodh, and A. Haldar, "Design and development of precipitate strengthened advanced high strength steel for automotive application," Mater. Sci. Eng. A, vol. 561, pp. 394-402, 2013.

[16] Y. Yu, H. Zhou, and J. Fu, "Research on agricultural product price forecasting model based on improved BP neural network," J. Ambient Intell. Humaniz. Comput., pp. 1-6, 2018.

[17] Y. Zhang and S. Na, "A novel agricultural commodity price forecasting model based on fuzzy information granulation and MEA-SVM model," Math. Probl. Eng., vol. 2018, 2018.

[18] L. Zhuang, H. Liu, J. Zhu, S. Wang, and Y. Song, "Comparison of Forecasting Methods for Power System Shortterm Load Forecasting Based on Neural Networks *," no. 61473174, pp. 114-119, 2016.

[19] W. Y. Chang, "Comparison of Three Short Term Wind Power Forecasting Methods," Adv. Mater. Res., vol. 684, pp. 671-675, 2013.

[20] H. Yu, T. Xie, S. Paszczynski, and B. M. Wilamowski, "Advantages of radial basis function networks for dynamic system design,” IEEE Trans. Ind. Electron., vol. 58, no. 12, pp. 5438-5450, 2011.

[21] A. K. Pamosoaji, P. T. Cat, and K.-S. Hong, "Sliding-mode and proportional-derivative-type motion control with radial basis function neural network based estimators for wheeled vehicles," Int. J. Syst. Sci., vol. 45, no. 12, pp. 2515-2528, 2014.

[22] T. J. Ai and V. Kachitvichyanukul, "A particle swarm optimisation for vehicle routing problem with time windows,” Int. J. Oper. Res., vol. 6, no. 4, pp. 519-537, 2009.

[23] E. F. Camacho and C. B. Alba, Model predictive control. Springer Science \& Business Media, 2013.

[24] W. Anggraeni et al., "Agricultural strategic commodity price forecasting using artificial neural network," 2018 Int. Semin. Res. Inf. Technol. Intell. Syst. ISRITI 2018, pp. 347-352, 2018.

[25] A. H. Nurcahyono, F. Nhita, D. Saepudin, and A. Aditsania, "Price prediction of chili in bandung regency using support vector machine (SVM) optimized with an adaptive neuro-fuzzy inference system (ANFIS)," 2019 7th Int. Conf. Inf. Commun. Technol. ICoICT 2019, pp. 1-6, 2019.

\section{BIOGRAPHY OF AUTHORS}

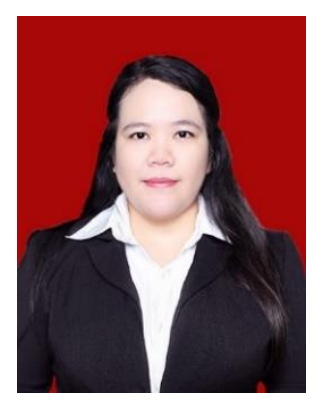

Sarifah is well-experienced in system development, business process re-engineering, and service excellence field. She graduated from School of Electrical and Informatics (STEI), Institut Teknologi Bandung (ITB), She actively joint research project in ITB in 2014-2016. She also worked as research and information system laboratory assistant in ITB. Now, she is an active researcher and lecturer in Department of Computer Science, Universitas Sriwijaya since 2016. Sarifah also has already published many research works in reputable journal and also international conferences. Now she has Scopus h-index $=4$, Google Scholar H-index $=5$, and WoS H-index $=2$. 

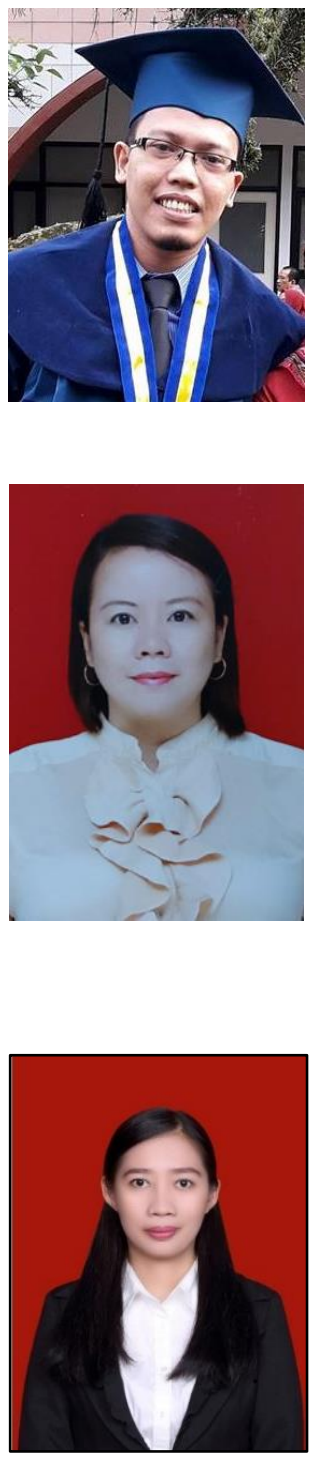

Taufiqurrahman received his Master degree from School of Electrical and Informatics (STEI) Institut Teknologi Bandung, Indonesia. Currently, working as an Information Technology Engineer at Cyber Defence Center Ministry of Defence Republic of Indonesia and conducting research related to software development, cyber threat and malware analysis. His research interest include Cellular Automata, system development, data visualization, social media analytics, cyber threat intelligence and malware analysis.

Silfi Iriyani is now a student of Agriculture Doctoral Program at Universitas Syiah Kuala. She has experiences in agricultural field, environment, forestry, socio-economics. She recently experienced in strengthening community related to the development of community forest in Aceh through Hutan Desa at 11 villages. Started from planning to guiding community forest to raise community income from non-timber forest products, raising awareness for conservation issue, socio-economic activities which include enhancement of women participation and role, adaptation and mitigation climate change issue, institutional development, training, and capacity building.

Dinda Lestarini is an active lecturer in Computer Science Faculty, Universitas Sriwijaya. She received master degree in Informatics from School of Electrical and Informatics, Institut Teknologi Bandung (ITB). Her research interest including knowledge manangement, business process management, and information technology service management. She has already produced a number of research papers in reputable journal and conference. She has Scopus h-index of 3 and WoS h-index of 2. Currently, she serves as the head of database and big data laboratory in Computer Science Faculty, Universitas Sriwijaya. 